\title{
Language development delay in 24-month-old children at a health care center of the City of Buenos Aires
}

\author{
Alejandro Blumenfeld, M.D., ${ }^{a} J o s e ́$ Carrizo Olalla, M.D., ${ }^{b}$ Sabrina I. D'Angelo, M.D., ${ }^{c}$ \\ Natalia S. González, M.D., ${ }^{c}$ Yael Sadras, M.D., ${ }^{c}$ Sandra Graizer, B.S., ${ }^{d}$ \\ Alejandro Macario, M.D. ${ }^{a}$ and Graciela Salamanco, M.D. ${ }^{e}$
}

\begin{abstract}
Introduction. Language development delay is a frequent challenge for pediatricians and other health care providers. The main objective of this study was to establish its prevalence among children attending a health care center.

Population and methods. The expressive vocabulary of 24-month-old children attending a health care center was assessed using the Spanishlanguage MacArthur-Bates Communicative Development Inventories, short form (Argentine version). The association between language delay and demographic, socioeconomic, behavioral/ emotional, and parental stress characteristics was analyzed. In children with expressive language delay, receptive vocabulary was assessed and possible underlying causes were studied (non-verbal cognitive delay, autistic spectrum disorders, middle ear pathology, and hearing impairment).
\end{abstract}

Results. Language development delay was observed in 16 out of 138 participants $(11.6 \%$; 95\% confidence interval: $6.2-17 \%$ ), significantly associated with a family history of language delay, parental stress, and problem behavior. Receptive vocabulary compromise was identified in 13 out of 16 children with language development delay, and 7 were suspected of autistic spectrum disorder, overall developmental delay, or both. A middle ear pathology was observed in 5 out of 9 studied children. The 9 participants who had an audiometry did not have pathological results based on this study's criteria.

Conclusions. Language development delay is a prevalent condition in our population and has been mainly associated with behavioral problems and a family history of language delay.

Key words: oral language development delay, primary health care, child development, autistic spectrum disorder, hearing impairment.

http: / / dx.doi.org/10.5546/ aap.2018.eng.242

To cite: Blumenfeld A, Carrizo Olalla J, D’Angelo SI, et al. Language development delay in 24-monthold children at a health care center of the City of Buenos Aires. Arch Argent Pediatr 2018;116(4):242-247.

\section{INTRODUCTION}

Since early childhood, children develop language milestones of increasing complexity, following a predictable sequence of speech-like sounds, syllables, and eventually words. ${ }^{1}$ Based on the ecological model, such development is determined by biological, hereditary, psychological, and socioeconomic factors. ${ }^{2}$ Although there is no specific definition for "language development delay," the term has been used in the scientific literature universally to identify children aged 18-36 months who fail to achieve the minimum expressive vocabulary milestones expected for their age and sex. It is a synonym for "language acquisition delay" and "early language delay". ${ }^{3}$ The more informal term "late talkers" is also widely used in the literature. ${ }^{4}$

No studies have been found in Argentina on the prevalence of language delay. In other countries, studies have been conducted that focused predominantly on middle and high socioeconomic level populations, which found a prevalence of $10-20 \%$.-8 Although the prognosis of these children is in general good, it has been estimated that approximately one third also have receptive vocabulary compromise, which increases their risk for language disorders later in childhood. ${ }^{9}$ In addition, there is a subset of children who have underlying causes of language delay, such as genetic disorders, intellectual disability, autistic spectrum disorders (ASDs), perinatal hypoxia or hearing impairment. ${ }^{1}$

The objective of this study was to determine the prevalence of language development delay in 24-month-old children at a health care center of the Autonomous City of Buenos Aires (CABA) and associated factors. 


\section{POPULATION AND METHODS}

This study was conducted between February 2015 and October 2016 at the Center for Health and Community Action (Centro de Salud y Acción Comunitaria, CeSAC) no. 44, a primary care health center located in the south of the CABA. Underlying causes were assessed with the collaboration of the Ear, Nose and Throat Department of Hospital General de Agudos "Parmenio Piñero" and the Department of Audiology of Hospital de Rehabilitación "Manuel Rocca," both also located in the CABA.

An observational, analytical, cross-sectional design was used. Children aged 24 months with a medical record at the CeSAC 44 were included. Exclusion criteria were hearing impairment, previous diagnosis of developmental disorders or ASD, intellectual disability-associated disorders (e.g., Down's syndrome), cerebral palsy, perinatal pathology that would have required mechanical ventilation or exchange transfusion, preterm or low birth weight (less than 2500 grams) infants, a history of meningitis, nonfebrile seizures or epilepsy, neurosurgery, congenital heart diseases, cancer, and living in a non-Spanish speaking or bilingual household (defined as a household where one of the parents spoke a language other than Spanish on a daily basis). These criteria were used in other studies to determine the prevalence of language delay among apparently healthy children. ${ }^{6-8,10}$

Participants were selected by convenience sampling and all those available were included consecutively. Participants were invited on the telephone and an appointment was made with one of the parents. Additionally, invitation notes were left at the houses located within 1000 meters of the CeSAC 44, posters were placed in the waiting room, and personal invitations were handed out.

The investigation was divided in 2 phases (Figure 1). In phase 1, all participants were studied. The primary outcome measure was expressive vocabulary assessed using the Spanish-language MacArthur-Bates Communicative Development Inventories, short form II (S-CDI SF-II) (Argentine version). This instrument was self-administered by one of the parents and consisted in identifying the words regularly used by the child out of a preselected list of 100 words. ${ }^{11}$ The instrument was validated in Mexico and, for this study, 12 out of the 100 words were culturally adapted to the local Spanish language during the pilot phase, with the authorization of the instrument's original authors and maintaining the original sense of the word. For example, the Spanish term "fósforos" was used instead of "cerillos" to mean "matches" or "arveja" instead of "chícharo" to refer to "peas". The same procedure had been used before with English language versions. ${ }^{7,12}$ The investigator of this study acted as a facilitator, as described in the instrument's user manual. The reference standards for each sex and age were used, which established the presence of language delay with a score below the $10^{\text {th }}$ percentile. Although the S-CDI SF-II also assessed the ability to combine words, this was not used because reference values were not available at the time of study initiation.
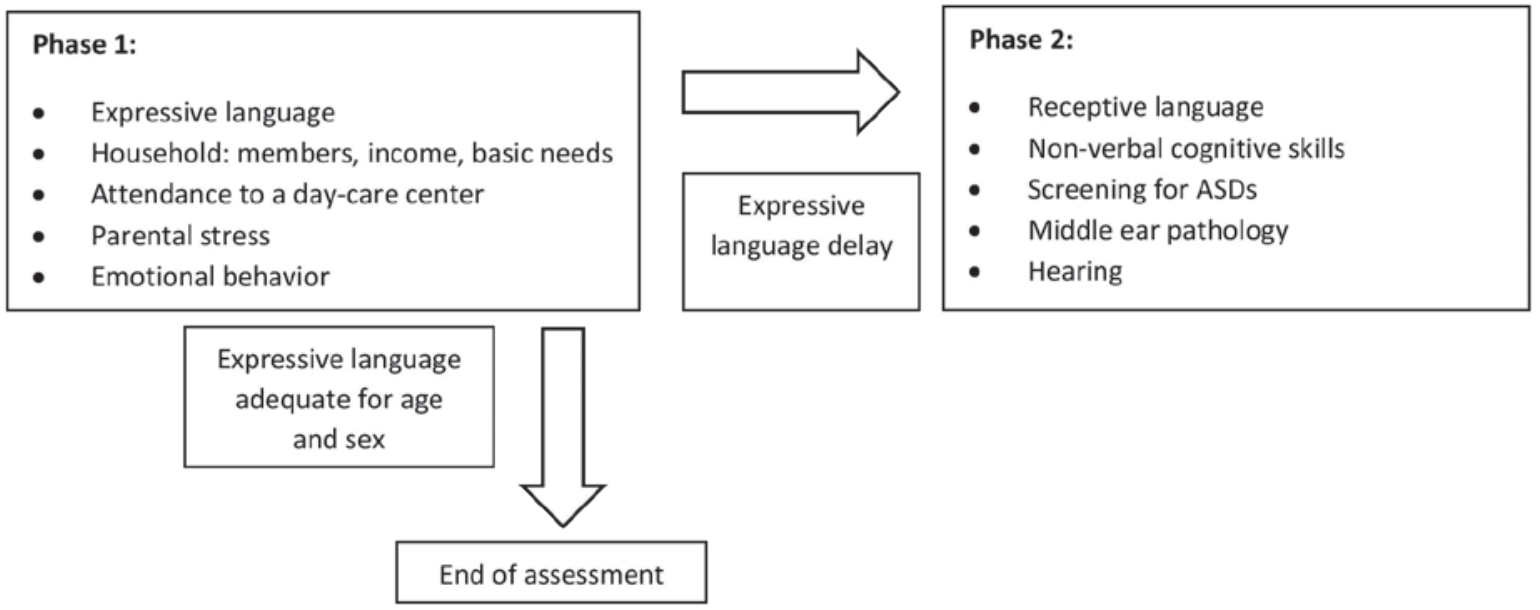

ASDs: autistic spectrum disorders. 
Independent outcome measures were recorded during phase 1 using a questionnaire and included sex, number of adults and siblings under 18 years sharing the household, level of maternal formal education (complete or incomplete secondary education), socioeconomic level, which measured household income (indigent, poor or not poor, according to official data) ${ }^{13}$ and unmet basic needs (UBNs) (overcrowding, inadequate housing, lack of toilet, school-aged children not attending school or 4 or more household members per employed member with a head of household who completed less than 3 years of primary school) ${ }_{1}^{14}$ attendance to a day-care center (in months), and a family history of language delay in first-degree relatives. The level of stress in relation to the parental role was also assessed using the Parenting Stress Index (PSI), an instrument validated in Spain ${ }^{15,16}$ and previously used in Argentina ${ }^{17}$ and in other studies on language delay. ${ }^{5,18}$ Based on the total score, the result was classified as normal or clinically significant stress. To assess behavioral and emotional problems, we used the Spanishlanguage version of the Childhood Behavior Checklist (CBCL) for ages $1.5-5,{ }^{19}$ validated in Argentina ${ }^{20}$ and also implemented in studies on language delay. ${ }^{21}$ Based on the total score, the result was classified as normal or problem behavior (within the clinical range). Each participant was assessed by a single investigator from a group of 4 pediatricians who were previously trained on data collection and how to administer the instruments mentioned above.

All participants who showed language delay during phase 1 were subsequently assessed during phase 2 . The objective of phase 2 was to identify receptive vocabulary compromise and the possible underlying causes of such delay. Receptive vocabulary was studied using the Spanish-language MacArthur-Bates Communicative Development Inventories, short form (S-CDI SF-II) (Argentine version). ${ }^{11}$ This instrument was self-administered: one of the parents identified the words his/her child understood out of a list of 104 words. Language was considered typical if the result was above the 50th percentile for 18 months old (maximum age as per the instrument's standards). For this version, and also with the original authors' authorization, 11 words were culturally adapted to the local Spanish language during the pilot phase. Another Spanish-language short form of the instrument was validated in Chile and showed adequate psychometric properties. ${ }^{22}$

Non-verbal cognitive skills were assessed using the Spanish-language version of the Cognitive Adaptive Test/Clinical Linguistic and Auditory Milestone Scale (CAT/CLAMS), ${ }^{23}$ recommended by the Ministry of Health of Argentina, ${ }^{24}$ which has been used locally. ${ }^{25}$ Results were classified as normal, suspicious or in the pathological range (suggesting an overall developmental delay). The possibility of a language delay secondary to ASD was assessed using the Spanish-language version of the Modified Checklist for Autism in ToddlersRevised with Follow up (M-CHAT-R/F), ${ }^{26}$ which has been validated in Argentina. ${ }^{27}$ The 3 instruments used in phase 2 were administered by the study's principal investigator.

For the ear examination, participants were assessed by an Ear, Nose, and Throat specialist from Hospital General de Agudos "Parmenio Piñero" using a binocular micro-otoscopy, a highly-sensitive device to detect ear disorders. ${ }^{28}$ The hearing test was done using a play-based pure tone audiometry (Kamplex ${ }^{\circledR}$ AD 229 audiometer) at Hospital de Rehabilitación "Manuel Rocca." If the participant was not collaborative, a free field audiometry or a visual reinforcement audiometry was done. The minimum hearing loss threshold was not used as cut-off point; instead, the criteria used for the National Screening Test (Prueba Nacional de Pesquisa, PRUNAPE) validation were adopted, ${ }^{29}$ which consider that a participant is pathological if he/she has mild hearing impairment (loss of 15-30 dB) in one ear and moderate hearing impairment (loss of 30$60 \mathrm{~dB}$ ) in the other.

\section{Ethical considerations}

This study was approved by the Research Ethics Committee of Hospital General de Agudos "Parmenio Piñero." An informed consent was obtained from the mother or father of each participant. Data confidentiality was warranted.

\section{Statistical analysis}

Considering a language delay prevalence of $10-20 \%$ established in prior studies, ${ }^{6,30}$ for an $\alpha=0.1$, the sample size was estimated at 138 participants.

A univariate analysis was done, for which proportions and confidence intervals (CIs) were described for categorical outcome measures, and medians and interquartile ranges were expressed for numerical outcome measures 
with an abnormal distribution. For the bivariate analysis, the $\chi^{2}$ test or Fisher's test was used to compare proportions (as applicable) and the Mann-Whitney test, to compare numerical outcome measures with an abnormal distribution between groups.

Data were processed using the Stata 11.2 statistical software (Statacorp LP ${ }^{\circledR} 2009, T X$, USA).

\section{RESULTS}

A total of 138 participants were included out of 994 candidates. The main reason for not participating was the impossibility to contact the candidate (missing or incorrect telephone number). Among contacted candidates, the 2 main exclusion criteria were a bilingual household and prematurity, and only 2 candidates refused the invitation to participate. No participants were excluded due to previously diagnosed developmental disorders or hearing impairment. Answers were provided by the mother in the case of 136 participants $(98.5 \%)$.

The characteristics of participants are described in Table 1. More than half were boys, and one third $(n=46 ; 33 \%)$ of participants did not share the household with siblings.

Based on the household income, $30(22 \%)$ participants lived in indigent households; $93(67 \%)$, in poor households; and $15(11 \%)$, in not poor households. In relation to day-care attendance, two thirds of participants $(n=91 ; 66 \%)$ never attended a day-care center, whereas those who did had a median attendance duration of 4 months (interquartile range: 3-10).

Language development delay was observed in 16 out of 138 participants (11.6\%; 95\% CI: 6.2$17 \%$ ). The prevalence of language delay was 5 times higher among participants with a family history of language delay and 4 times higher among those with problem behavior according to the CBCL. Statistically significant differences were also observed in terms of parental stress, although the size of the association was smaller (prevalence ratio [PR]: 2.6; 95\% CI: 1-6.5). During phase 2, receptive vocabulary compromise was observed in 13 out of the 16 participants. Four participants had non-verbal cognitive skills, which were suspected to be pathological, and 1, in the pathological range. In turn, 4 participants were suspected of ASD. A middle ear examination was done in 9 participants; 4 results were normal, 4 participants had otitis media with bilateral effusion, and 1 had unilateral tympanic membrane retraction. Finally, an audiometry was done in the 9 participants and results were normal in all cases.

\section{DISCUSSION}

In this study, language development delay was identified in approximately 1 out of every 10 children, which is equivalent to the proportion observed in other studies conducted in populations with a greater representation of middle and high socioeconomic levels. ${ }^{5-8}$ This condition is observed in the pediatric office on a day-to-day basis so it is important to identify and assess it in a timely manner. ${ }^{31}$

The association found between language delay and behavioral disorders has been observed before, as well as the relation with parental stress and a family history of delay..$^{5,18,21}$ The relationship between the socioeconomic level and the language development delay is still controversial and, although there is evidence supporting such relationship, ${ }^{32}$ our findings suggest the contrary, similar to those of other

TABLE 1. Results of the initial assessment (phase 1, based on the presence of language development delay, $n=138$ )

\begin{tabular}{|c|c|c|c|c|c|}
\hline & $\begin{array}{c}\text { Total } \\
(\mathrm{n}=138)\end{array}$ & $\begin{array}{c}\text { Typical language } \\
(n=122)\end{array}$ & $\begin{array}{l}\text { Language delay } \\
\qquad(n=16)\end{array}$ & $\begin{array}{c}\text { PR } \\
(95 \% \mathrm{CI}) \\
\end{array}$ & $p$ \\
\hline \multicolumn{6}{|l|}{$N(\%)$ or median (interquartile range) } \\
\hline Male sex & $76(55)$ & $67(55)$ & $9(56)$ & & 0.9 \\
\hline Mother completed secondary education & $64(46)$ & $56(46)$ & $8(50)$ & & 0.8 \\
\hline Adults sharing the household & $2(2-3)$ & $2(2-3)$ & $2(2-3.5)$ & & 0.6 \\
\hline Siblings sharing the household & $1(1-2)$ & $1(0-2)$ & $1(0-1.5)$ & & 0.8 \\
\hline Poor/indigent (based on income) & $123(89)$ & $110(90)$ & $13(81)$ & & 0.3 \\
\hline Unmet basic needs & $72(52)$ & $66(54)$ & $6(38)$ & & 0.2 \\
\hline Attendance to a day-care center (in months) & $0(0-3)$ & $0(0-3)$ & $0(0-1)$ & & 0.7 \\
\hline Family history of language delay & $40(29)$ & $30(25)$ & $10(63)$ & $4.1(1.6-10.5)$ & 0.002 \\
\hline Parental stress & $26(19)$ & $20(16)$ & $6(38)$ & $2.6(1-6.5)$ & 0.04 \\
\hline Problem behavior (in the clinical range) & $6(4)$ & $3(2)$ & $3(19)$ & $5.1(2-13.1)$ & 0.003 \\
\hline
\end{tabular}

PR: prevalence ratio; CI: confidence interval. 
publications. ${ }^{5-8}$ In addition, no association was observed between language delay and attending a day-care center, like other authors $\mathrm{did}^{6}{ }^{6}$ although a recent study evidenced such relationship. ${ }^{8}$ It was not possible to demonstrate the association with the number of people sharing the household (children or adults) either, contrary to the theory of family resource dilution ${ }^{33}$ and the concept that a greater number of siblings may have a positive influence on early vocabulary.

A concurrent receptive vocabulary compromise was observed among participants with language development delay. The high prevalence observed is striking compared to previous data that showed that one third of participants were affected. The different approaches to measure receptive vocabulary hinder the possibility of making comparisons in this regard. ${ }^{30}$

It is worth noting that none of the 9 participants with language delay had a hearing disorder based on the criteria used in this study, even those who had otitis media with effusion. Although it has been proposed to perform a formal assessment of all children with language development delay, ${ }^{10}$ the optimal strategy to select candidates for an audiometry requires further studies designed to that end. In addition, based on the identification of language development delay, there were some suspected cases of ASD and overall developmental delay that had not been previously detected, which provided even more support to the language screening proposed for pediatric preventive care visits. In relation to this, it is worth mentioning that, to date, the extent of scientific evidence on the risks and benefits of performing a language delay screening in the general population is uncertain. ${ }^{34}$

This study has certain limitations. Although the MacArthur-Bates CDI was not validated in Argentina, other Spanish-language versions reported a validity equivalent to the Englishand other language versions. ${ }^{12}$ Although selfadministered questionnaires are influenced by the perspectives of the respondent, they offer the advantage that the respondent knows the extent of the child's vocabulary in his/ her natural setting for longer periods compared to a professional observer who is not familiarized with the child in an unknown setting that may inhibit his/her responses. In addition, we used the M-CHAT and the CAT/CLAMS instruments, which despite not offering a confirmatory diagnosis, are highly sensitive and specific to detect ASD and overall developmental delay. ${ }^{23,27}$ It was not possible to analyze the association between language delay and studied outcome measures using a multivariate analysis due to the sample size limitations, so we only used a bivariate analysis. Finally, almost half of participants with language delay did not complete the assessment corresponding to phase 2, which evidenced the difficulties in accessibility and adherence also observed in other countries. ${ }^{35}$

Among the main strengths of this study, it is worth noting the population base at the primary care level, the multidimensional approach based on the ecological model with instruments equivalent to those used in the international bibliography and mostly locally validated, as well as the characterization of children with language delay in terms of receptive vocabulary compromise and possible underlying causes.

The possibility of extrapolating results to other population sectors of the CABA could be considered, especially to low socioeconomic levels who seek care at the CeSAC. Although the participants' ethnic origin was not studied, to date, the role of this characteristic (considered regardless of socioeconomic level) as a determinant of language development is uncertain. ${ }^{8}$

\section{CONCLUSIONS}

Language development delay is a prevalent condition in our population and has been mainly associated with behavioral problems and a family history of language delay.

\section{Acknowledgments}

We would like to thank Donna JacksonMaldonado for her generosity and willingness.

\section{REFERENCES}

1. Feldman HM, Messick C. Language and speech disorders. In: Carey W, Crocker A, Elias E, et al. DevelopmentalBehavioral pediatrics. $4^{\text {th }}$ ed. Philadelphia:Saunders-Elsevier; 2009.Pages717-29.

2. Bornstein MH, Haynes MO, Painter KM. Sources of child vocabulary competence: a multivariate model. J Child Lang 1998;25(2):367-93.

3. Hawa VV, Spanoudis G. Toddlers with delayed expressive language: An overview of the characteristics, risk factors and language outcomes. Res Dev Disabil 2014;35(2):400-7.

4. Thal D. Late-talking toddlers: Are they at risk? San Diego, CA: San Diego State University; 2000.

5. Horwitz SM, Irwin JR, Briggs-Gowan MJ, et al. Language delay in a community cohort of young children. J Am Acad Child Adolesc Psychiatry 2003;42(8):932-40.

6. Zubrick SR, Taylor CL, Rice ML, et al. Late language emergence at 24 months: an epidemiological study of 
prevalence, predictors and covariates. J Speech Lang Hear Res 2007;50(6):1562-92.

7. Reilly S, Bavin EL, Bretherton L, et al. The Early Language in Victoria Study (ELVS): A prospective, longitudinal study of communication skills and expressive vocabulary development at 8, 12 and 24 months. Int J Speech Lang Pathol 2009;11(5):344-57.

8. Collisson BA, Graham SA, Preston JL, et al. Risk and protective factors for late talking: An epidemiologic investigation. J Pediatr 2016;172:168-74.

9. Rescorla L. Late talkers: Do good predictors of outcome exist? Dev Disabil Res Rev 2011;17(2):141-50.

10. Buschmann A, Jooss B, Rupp A, et al. Children with developmental language delay at 24 months of age: results of a diagnostic work-up. Dev Med Child Neurol 2008;50(3):223-9.

11. Jackson-Maldonado D, Marchman VA, Fernald LCH. Short-form versions of the Spanish MacArthurBates Communicative Development Inventories. Appl Psycholinguist 2013;34(4):837-68.

12. Dale PS, Penfold M. Adaptations of the MacArthur-Bates CDIInto Non-U.S. English Languages. 2011. [Accessed on: March, 8th, 2017]. Available at: http:/ / mb-cdi.stanford. edu/documents / AdaptationsSurvey2011.pdf.

13. Dirección General de Estadística y Censos, Ministerio de Hacienda, Gobierno de la Ciudad de Buenos Aires. Canastas de consumo de la Ciudad de Buenos Aires. Metodología y cálculos iniciales. 2009. [Accessed on: March, 8th, 2017]. Available at: https: / / www.estadisticaciudad.gob.ar/eyc/ wp-content/uploads/2015/04/canastas_consumo_2010_ enero.pdf.

14. Equipo de trabajo de la Encuesta de Hogares y Empleo. Dirección Provincial de Estadística de la provincia de Buenos Aires. Métodos de Medición de la Pobreza. Conceptos y aplicaciones en América Latina. Entrelíneas de la Política Económica 2010;26(4):31-41. [Accessed on: March, 8th, 2017]. Available at:http: / / sedici.unlp.edu.ar/ bitstream/handle/10915/15399/Documento_completo. pdf?sequence $=1$.

15. Abidin RR. Parenting Stress Index (PSI) manual. $3^{\text {rd }}$ ed. Charlottesville, VA: Pediatric Psychology Press; 1995.

16. Díaz-HerreroA, López Pina JA, Pérez-López J, et al. Validity of the Parenting Stress Index-short form in a sample of Spanish fathers. Span J Psychol 2011;14(2):990-7.

17. Basa JA. Estrés parental con hijos autistas. Un estudio comparativo. [Dissertation]. Paraná: Universidad Católica Argentina; 2010. [Accessed on: March, 8th, 2017]. Available at: http: / / bibliotecadigital.uca.edu.ar/repositorio/ tesis / estres-parental-con-hijos-autistas.pdf.

18. IrwinJR, Carter AS, Briggs-Gowan MJ. The social-emotional development of "late-talking" toddlers. J Am Acad Child Adolesc Psychiatry 2002;41(11):1324-32.

19. Achenbach TM, Rescorla LS. Manual for the ASEBA Preschool Forms \& Profiles. Burlington, VT: University of Vermont, Research Center for Children, Youth \& Families; 2000.

20. VázquezN,Samaniego VC. ElChild BehaviorChecklist para niños en edad preescolar (CBCL 1 1 $12-5$ ): su estandarización en población urbana de argentina. Trabajo presentado en el VI Congreso Internacional de Investigación y Práctica
Profesional en Psicología, XXI Jornadas de Investigación Décimo Encuentro de Investigación en Psicología del MERCOSUR; 27 a 29 de noviembre de 2014. Buenos Aires, Universidad de Buenos Aires; 2014.

21. Carson DK, Klee T, Perry CK, etal. Comparisons of children with delayed and normal language at 24 months of age on measures of behavioral difficulties, social and cognitive development. Infant Ment Health J 1998;19(1):59-75.

22. Farkas Ch. Inventario del desarrollo de habilidades comunicativas MacArthur-Bates (CDI): propuesta de una versión abreviada. Univ Psychol 2011;10(1):245-62.

23. Accardo PJ, Capute AJ. The Capute scales: Cognitive Adaptive Test/Clinical Linguistic \& Auditory Milestone Scale(CAT/CLAMS). Baltimore: Brookes Publishing; 2005.

24. Couceiro C, Escandar A, Novali L, et al. Evaluación del neurodesarrollo. In: Unidad Coordinadora Ejecutora de Programas Materno Infantiles y Nutricionales, Ministerio de Salud de la Nación. Guía de Seguimiento del Recién Nacido de Riesgo. 2001: 66-92. [Accessed on: December 10th, 2014]. Available at: http: / / docshare01.docshare.tips / files / 18704/187040359.pdf.

25. Lejarraga $\mathrm{H}$, Berardi $\mathrm{C}$, Ortale $\mathrm{S}$, et al. Crecimiento, desarrollo, integración social y prácticas de crianza en niños que viven con sus madres en prisión. Arch Argent Pediatr 2011;109(6):485-91.

26. Robins D, Fein D, Barton M. Lista de Chequeo Modificada para Deambuladores, Revisada con Seguimiento. 2009. [Accessed on: March, 8th, 2017]. Available at: http:// mchatscreen.com/wp-content/uploads / 2015/05/MCHAT-R_F_Spanish_Argentina_Uruguay.pdf.

27. Manzone LA. Adaptación y validación del Modified Checklist for Autism in Toddlers para población urbana argentina. Psicodebate 2013;13:79-105.

28. Rogers DJ, Boseley ME, Adams MT, et al. Prospective comparison of handheld pneumatic otoscopy, binocular microscopy, and tympanometry in identifying middle ear effusions in children. Int J Pediatr Otorhinolaryngol 2010;74(10):1140-3.

29. Pascucci MC, Lejarraga H, Kelmansky D, etal. Validación de la prueba nacional de pesquisa de trastornos de desarrollo psicomotor en niños menores de 6 años. Arch Argent Pediatr 2002;100(5):374-84.

30. Desmarais C, Sylvestre A, Meyer F, et al. Systematic review of the literature on characteristics of late-talking toddlers. Int J Lang Commun Disord 2008;43(4):361-89.

31. Camarasa A. Trastornos de la comunicación y el lenguaje: detección temprana. In: Sociedad Argentina de Pediatría. PRONAP; 3, 2010.Pages58-80.

32. Hoff E. The specificity of environmental influence: Socioeconomic status affects early vocabulary development via maternal speech. Child Dev 2003;74(5):1368-78.

33. Downey DB. Number of siblings and intellectual development. Am Psychol 2001;56(6-7):497-504.

34. Siu AL. Screening for speech and language delay and disorders in children aged 5 years or younger: USPreventive Services Task Force recommendation statement. Pediatrics 2015;136(2):e474-81.

35. Brown CM, Beck AF, Steuerwald W, et al. Narrowing care gaps for early language delay: A quality improvement study. Clin Pediatr (Phila) 2016;55(2):137-44. 